\title{
Danza interacción como agente re-ligante ser humano-naturaleza: propuestas desde una educación escolar transformadora*
}

\author{
Dance interaction as binding factor human-nature: proposals since a \\ transforming school education \\ Dança interativa como agente de re-ligação entre ser humano-natureza: propostas \\ com sentido desde uma educação escolar transformadora
}

\begin{abstract}
Loreto Libuy Castro, ${ }^{\mathrm{a}}$ Otto Lührs Middleton ${ }^{\mathrm{b}}$
aUniversidad Austral de Chile, Facultad de Filosofía y Humanidades, Instituto de Filosofía y Estudios Educacionales. Campus Isla Teja,Valdivia. Telf.: (56-63) 293823. Correo electrónico: loretolibuy@ gmail.com

bUniversidad Austral de Chile, Facultad de Filosofía y Humanidades, Instituto de Filosofía y Estudios Educacionales. Campus Isla Teja,Valdivia. Telf.: (56-63) 293815. Correo electrónico: otto.luhrs@ gmail.com
\end{abstract}

\begin{abstract}
RESUMEN
Reflexionar acerca de las transformaciones educativas al danzar, desde una mirada holística del ser humano y su relación con el entorno, es el desafío constante de este artículo, donde nuevas propuestas pedagógicas convocan tanto a estudiantes como a profesores a indagar en la percepción, la incertidumbre y la identidad como elementos de trascendencia humana. La invitación específica es hacia la experiencia de la "Danza Interacción", modalidad emergente que se caracteriza por la investigación corporal en relación a espacios no convencionales como escenarios creativos de despliegues artísticos. Desde estos objetivos, aparece la complejidad y el contacto con la naturaleza como componentes relacionales y complementarios de la danza. Le Breton (2006), Santiago (2004), Morin (2001; 2005), Berman (2004), Boff (2000; 2002), Reichman (2005) y Holzapfel (2005), son algunos de los autores que aportan a esta discusión.
\end{abstract}

Palabras clave: danza interacción, ser humano-naturaleza, transformación eco-cultural, educación.

\begin{abstract}
Think about the educational transformations upon dancing, from a holistic look of the human being and their relation with the environment, this is the constant challenge of this article where new pedagogical proposals call students and professors to investigate in the perception, the uncertainty, and the identity as elements of human significance. The specific invitation is toward the interaction dance experience, emerging modality that is characterized for the corporal investigation, related to not conventional spaces as creative settings of unfold artistic. Since these objectives, the complexity and the contact with the nature appear as complementary and relational components of the dance. . Le Breton (2006), Santiago (2004), Morín (2001; 2005), Berman (2004), Boff (2000;2002), Reichman (2005), y Holzápfel (2005) are some of the authors that contribute to this discussion.
\end{abstract}

Key words: dance interaction, human-nature, eco-cultural transformation, education.

\section{RESUMO}

Objetiva-se pensar detidamente sobre os significados e transformações da dança, a partir de uma visão holística do ser humano e sua relação com o entorno em busca de novas propostas pedagógicas que convoquem, alunos e professores da área da educação, especialmente aqueles da área da Educação Física, a descobrirem percepção, incerteza e identidade

* $\quad$ Este artículo fue solicitado por la Revista Estudios Pedagógicos en diciembre del 2011 en el contexto del proyecto de Investigación FONDECYT (Fondo de Investigación Científica y Tecnológica) No 11110016 , titulado "Educación Física y su función de transformación de las desigualdades sociales: profesorado del área y documentación ministerial”. El artículo fue aceptado en junio de 2012. 
como geradores de significado. O convite é específico para a experiência de dança interativa, modalidade emergente que se caracteriza pela investigação corporal em relação a espaços não convencionais como cenas criativas de movimento artísticos. A partir de estes objetivos, surgem a complexidade e o contato com a natureza como componentes relacionais e complementares da dança. Le Breton (2006), Santiago (2004), Morin (2001, 2005), Berman (2004), Boff (2000, 2002), Reichman (2005) e Holzápfel (2005), entre outros, contribuem para esta discussão.

Palavras chave: dança interativa, ser humano-natureza, transformação eco-cultural, educação.

\section{ANTECEDENTES PROBLEMÁTICOS}

\section{1 ¿SOMOS LOS SERES HUMANOS NATURALEZA?}

Antes de referirse a la primera pregunta que desafía la problemática de este artículo, se hace necesario acotar que, debido al componente arriesgado, en términos semánticos, de lo que entenderemos por danza interacción y su tendencia relacional con los entornos, quisiéramos comenzar por tensionar esta propuesta desde la comprensión si somos o no naturaleza, como una forma de abrir la discusión hacia espacios reflexivos de educación y transformación eco-cultural.

Para nosotros como educadores, y por lo tanto como seres que co-habitamos este planeta, esta interrogante se plantea una vez instalada la problemática en cuestión, a consecuencia de la gran capacidad que tenemos los humanos de intervenir en los procesos naturales y sobre todo de los efectos constatados en el ejercicio de esta capacidad.

$\mathrm{Al}$ responder afirmativamente la pregunta que titula este apartado, y asumiendo que los seres humanos somos naturaleza, surgen dificultades semánticas para utilizar las palabras "natural" y "artificial". Normalmente entenderíamos lo "natural" como aquello que existe en independencia de la intervención humana; y artificial como antónimo sería igual a "no natural", aquello que existe producto del accionar humano; entonces caemos en una contradicción, pues no podemos concebir como algo "no natural", el acto de un ser que es naturaleza. Así podríamos concluir que todo lo que hace el ser humano es natural y que, por tanto, artificial no es un antónimo sino una subcategoría de lo natural. Pero nos encontramos con un rechazo instintivo a categorizar, como naturales, actos humanos tales como el uso de defoliantes, el "agente naranja" para eliminar la selva o el intento de modificar las condiciones atmosféricas para aumentar la intensidad y duración de las lluvias monzónicas en la Guerra de Vietnam; o el incendio deliberado de más de setecientos pozos petroleros por Sadam Husein en la Guerra del Golfo, que constituye un empleo de la contaminación a gran escala como táctica bélica (Reichmann 2005: 254), y otra infinidad de actos humanos, que tienen el provocar daño global y transgeneracional como denominador común. Así, lo que comenzó con una seductora frase, nos puede llevar a coincidir con lo expresado por Savater, cuando señala que "el plástico es tan natural como la miel" (Cit. en Reichmann, 2005: 140).

Por el contrario, si aceptáramos que el ser humano no es naturaleza, entonces todo lo que hace, incluyendo comer y digerir, dormir o descansar, jugar, aprender, reproducirse e incluso amar, sería algo no natural. Y el dilema entonces sería otro, igual de complejo (Reichmann, 2005: 140).

Es el mismo Reichmann quien nos propone algunas luces para resolver este acertijo al señalar un total de rasgos sobre la relación del ser humano con el cosmos que habita, entre los cuales existen semejanzas y diferencias con los otros seres. Dentro de las semejanzas, señala que compartimos la misma historia evolutiva sobre la tierra; existimos dentro de 
límites espacio-temporales; somos finitos y vulnerables; somos interdependientes (en la naturaleza todo está relacionado con todo); aspiramos a la auto-conservación; poseemos un conjunto de condiciones bajo las cuales nos desarrollamos óptimamente; existe un estar bien que es propio de nuestra especie biológica y somos realidades sintientes, capaces de sufrir y de gozar, semejanza esta particular con los animales.

Con respecto a las diferencias, indica que sólo los seres humanos somos agentes morales (condición derivada del lenguaje articulado, racionalidad, autoconciencia plenamente desarrollada), y sólo los seres humanos hemos creado una tecnociencia con capacidad destructora global, al punto de convertirnos en una fuerza geológica planetaria.

Si fusionamos las dos diferencias en una sola, nos encontramos con que los seres humanos somos una fuerza geológica planetaria moral, es decir, podemos elegir tanto la magnitud como la orientación de las intervenciones con las cuales vamos manifestando las semejanzas. La magnitud va desde el efecto más ínfimo imaginable, hasta la alteración de todo lo terráqueo; en tanto, la orientación se define según la intervención, sea creadora o destructora de vida. Por tanto, resulta más coherente con nuestra poderosa y diversa capacidad electiva, reconocer el ser o no ser naturaleza no como una dicotomía, sino como un abanico de posibilidades intermedias entre estos dos polos, que se resuelve de manera individual o grupal, pero no para toda la especie humana. Así, la pregunta, ¿somos los seres humanos naturaleza? se reemplaza por ¿qué tan naturaleza soy? o bien, ¿qué tan naturaleza es el grupo de humanos al cual pertenezco?

Pero para llegar al final de nuestra reflexión y con ella definir nuestra postura frente al título de este apartado, consideraremos lo vertiginoso y heterogéneo de los cambios de la relación humanidad y naturaleza de los últimos siglos. Cambios que pueden suceder también a nivel individual. Por tanto, comprenderemos la relación de la persona, de un grupo o de la humanidad toda con la naturaleza, ya no como una situación estacionaria sino más bien como una tendencia. Es decir, podremos responder "estoy siendo cada vez más naturaleza" o también lo contrario.

En este océano incierto y particular de comprensión, en un mundo donde el poder electivo personal se encuentra distorsionado, confundido y acallado, nos preguntamos en qué medida la persona del siglo XXI está consciente de la magnitud y orientación de los efectos de su existencia. La danza en general y la danza interacción en particular, aparecen como una posibilidad de sensibilización de la relación de la persona con su entorno. Creemos habitar un tiempo de búsqueda de acciones que, en primer lugar, provoca un darse cuenta del estado de des-ligación de humanidad y naturaleza, y a continuación identifica fórmulas para re-ligarnos con el todo. Conforme a lo planteado, en el siguiente apartado se plantea una revisión comparada de tres tendencias dancísticas, desde donde revisaremos el potencial re-ligante de la danza interacción.

\subsection{PERCEPCIONES CONVENCIONALES DE LA DANZA Y CRISIS ESCOLAR}

Luego de recoger piezas que ayudarán a construir lo que pretendemos compartir, se encuentra que la forma desordenada -inorgánica de ser y estar en este mundo- es una constante que precisa la emergencia de la armonía, y es en esta senda de interrogantes, desorganizaciones e inquietudes, donde como profesores y esencialmente como humanos inquietos por comprender algunos fenómenos educativos, nos detenemos a reflexionar sobre la danza como una forma vital de desarrollo, donde la comunicación con el medio 
o más bien la re-ligación con la naturaleza, despierta en nuestros intereses más profundos, nuevos elementos pedagógicos que podrían encaminar hacia una transformación eco-cultural. Sin embargo, existen algunas técnicas dancísticas convencionales que más que vincular e integrar al ser humano, tienden, desde nuestra perspectiva, a disociar, des-naturalizar y discriminar el accionar de las personas, donde la técnica se destaca por sobre la espontaneidad, los movimientos se repiten una y otra vez hasta lograr la perfección, siendo la anatomía y la habilidad del bailarín, características fundamentales al momento de conformar un elenco, y en este sentido Libuy (2007: 91) señala que "si no buscamos el verdadero sentido de danzar en la escuela, será una crónica de muerte anunciada". Para ser más exactos, nos referimos a la danza académica, también conocida como danza clásica.

\subsubsection{DANZA ACADÉMICA, DANZA CONTEMPORÁNEA, DANZA INTERACCIÓN}

Desde la reflexión anterior, el siguiente cuadro define las características y conceptos de lo que tradicionalmente se conoce como danza académica versus danza contemporánea, incorporándose también una nueva propuesta llamada danza interacción como una manera de contextualizar esta discusión. Es importante señalar que las dos primeras tendencias corresponden básicamente a los planteamientos de Castañer (2000) y Cifuentes (2008;

\begin{tabular}{|c|c|c|}
\hline DANZA ACADÉMICA & $\begin{array}{c}\text { DANZA } \\
\text { CONTEMPORÁNEA }\end{array}$ & DANZA INTERACCIÓN \\
\hline $\begin{array}{l}\text { Expresión e interpretación } \\
\text { se dan generalmente en } \\
\text { escenarios convencionales. }\end{array}$ & $\begin{array}{l}\text { Expresión e interpretación } \\
\text { se pueden dar en cualquier } \\
\text { encuadre argumental o } \\
\text { contextual. }\end{array}$ & $\begin{array}{c}\text { Propuesta emergente, } \\
\text { perteneciente a las } \\
\text { variadas formas de danza } \\
\text { contemporánea, intentando } \\
\text { diferenciarse de lo que } \\
\text { se entiende por danza } \\
\text { intervención, en búsqueda } \\
\text { de la re-ligación con los } \\
\text { entornos. }\end{array}$ \\
\hline $\begin{array}{l}\text { Búsqueda de ejercicios } \\
\text { ligeros a través de saltos y } \\
\text { giros. }\end{array}$ & $\begin{array}{l}\text { Búsqueda de ejercicios } \\
\text { orgánicos y fluídos, por } \\
\text { medio de la investigación } \\
\text { corporal de acciones } \\
\text { cotidianas. }\end{array}$ & $\begin{array}{c}\text { Búsqueda de ejercicios } \\
\text { orgánicos, por medio de } \\
\text { la investigación histórico- } \\
\text { cultural de los entornos, } \\
\text { con un fuerte énfasis en } \\
\text { la conexión corporal y } \\
\text { emocional que provocan } \\
\text { éstos. }\end{array}$ \\
\hline $\begin{array}{c}\text { Verticalidad y movimientos } \\
\text { aéreos. }\end{array}$ & $\begin{array}{c}\text { Transversalidad y } \\
\text { movimientos en suelo. }\end{array}$ & $\begin{array}{c}\text { Transversalidad y } \\
\text { movimientos en contacto } \\
\text { con la vida. }\end{array}$ \\
\hline
\end{tabular}




\begin{tabular}{|c|c|c|}
\hline $\begin{array}{l}\text { Preparación técnica que } \\
\text { sobrepasa las fronteras del } \\
\text { propio eje corporal. }\end{array}$ & $\begin{array}{l}\text { Preparación que invita } \\
\text { al riego, el desafío y la } \\
\text { superación de límites } \\
\text { corporales y emocionales. }\end{array}$ & $\begin{array}{l}\text { Preparación que invita } \\
\text { al riesgo, el desafío y } \\
\text { la superación de límites } \\
\text { corporales y emocionales, } \\
\text { cuidando siempre los } \\
\text { entornos vitales. }\end{array}$ \\
\hline $\begin{array}{l}\text { Trabajo estandarizado y } \\
\text { delimitado por principios } \\
\text { establecidos de la técnica. }\end{array}$ & $\begin{array}{c}\text { Trabajo de improvisación } \\
\text { y sensibilidad con los } \\
\text { espacios. }\end{array}$ & $\begin{array}{l}\text { Trabajo de sensibilidad con } \\
\text { los espacios, el entorno y } \\
\text { los semejantes. }\end{array}$ \\
\hline $\begin{array}{l}\text { Cualidades del cuerpo } \\
\text { orientadas hacia la } \\
\text { coordinación y la } \\
\text { flexibilidad. }\end{array}$ & $\begin{array}{l}\text { Cualidades orientadas hacia } \\
\text { la conciencia corporal, la } \\
\text { ubicación temporo-espacial } \\
\text { y las senso-percepciones. }\end{array}$ & $\begin{array}{l}\text { Cualidades orientadas hacia } \\
\text { la in-conciencia corporal y } \\
\text { las senso-percepciones. }\end{array}$ \\
\hline $\begin{array}{l}\text { Vestuarios de altos costos } \\
\text { económicos, caracterizados } \\
\text { por la elegancia y } \\
\text { uniformidad de sus } \\
\text { atuendos. }\end{array}$ & $\begin{array}{l}\text { Vestuarios de bajos costos } \\
\text { económicos, caracterizados } \\
\text { por la cotidianeidad } \\
\text { e informalidad de sus } \\
\text { atuendos. }\end{array}$ & $\begin{array}{c}\text { Vestuarios sutiles y ligeros, } \\
\text { caracterizados por la piel y } \\
\text { la posibilidad de incorporar } \\
\text { las sensaciones climáticas y } \\
\text { atmosféricas al bailar. }\end{array}$ \\
\hline $\begin{array}{c}\text { Tendencia hacia la } \\
\text { elevación y el despegue del } \\
\text { suelo. }\end{array}$ & $\begin{array}{l}\text { Tendencia hacia el apego } \\
\text { con la tierra. }\end{array}$ & $\begin{array}{l}\text { Tendencia hacia } \\
\text { la inmanencia y } \\
\text { trascendencia. }\end{array}$ \\
\hline
\end{tabular}

Cuadro 1. Comparación entre las distintas tendencias en danza

2009), mientras la tercera es un primer acercamiento a lo que intentamos levantar como posibilidad corporal pedagógica.

Luego de estas descripciones, contradictorias y complementarias, podemos visualizar que la manifestación "danza" necesita reflexiones que conlleven a nuevas propuestas, apareciendo de este modo la "danza interacción" como posibilidad que releva y supera el componente rupturista de la danza contemporánea tradicional, asumiendo un rol trascendente y significante que invita a contemplar la vida desde escenarios bióticos.

\subsubsection{Danza en la problemática educativa actual}

Para García (1997), optar por la danza como pedagogía nos exige entender y reconocer nuestra propia corporeidad de adultos, tanto a modo de reflexión como de auto-descubrimiento y eliminación de límites socialmente impuestos. Desde esta mirada, y haciendo una pequeña analogía de nuestros comportamientos humanos, se descubre que los actuales niños y adolescentes escolares se encuentran en una época de difícil comprensión cósmica, donde la falta de lógica y consecuencia que tenemos los adultos frente a la vida desencanta y desilusiona a este grupo etáreo, produciendo fuertes resistencias hacia la tradicional escuela, donde se obtiene como resultado constantes agresiones y claras manifestaciones de indiferencia al momento de querer comunicarnos. 
La desesperación de profesores y padres por pretender que los jóvenes sean respetuosos, choca con la contradicción de no ofrecerles un modelo convivencial en su entorno adulto, coherente con las conductas que a ellos se les demanda. En el día a día no somos capaces de respetarnos entre nosotros, ni mucho menos amarnos de manera espontánea y desinteresada. Por el contrario, diplomáticos y presidentes se descalifican; hombres asesinan y golpean a sus esposas; en las escuelas se disminuyen los espacios para la educación del ocio saludable y la creatividad, aumentando horas de lenguaje, matemáticas, lenguas extranjeras y estructurando la industria educativa en función del SIMCE y PSU, ${ }^{1}$ incluyéndose actualmente en estas pruebas estandarizadas la educación física, pero no los deportes y la recreación; luchamos por un mundo más limpio al tiempo que la energía se derrocha y llenamos nuestra vida de productos químicos que más bien dañan nuestros cuerpos y entornos, oliendo a rexona, a colgate o a perfumes, pero en ningún caso a tierra, sudor, piel y lluvia; nos quejamos del mal uso y abuso de internet y de televisión en niños y niñas, sin embargo al momento de distraer el llanto de un bebé encendemos la televisión para que aparezcan dibujos animados que hipnotizan e idiotizan las conexiones neuronales de los infantes.

Entonces, ¿cuál es el trasfondo de la problemática educacional? ¿en qué momento nos detenemos a reflexionar sobre los verdaderos sentidos que le vamos dando a más y nuevas metodología de trabajo pedagógico? ¿de qué sirve una nueva propuesta en el modo de hacer danza escolar? ¿es posible una verdadera transformación eco-cultural desde el mundo escolar? Para intentar desenredar este entretejido de incertidumbres educativas, pondremos en tensión algunos conceptos claves que convocan esta discusión, comenzando por comprender qué entendemos por "transformación", y también la noción de "eco-cultural" como significado ampliado de lo meramente social.

\subsection{LA ESCUELA SE RESISTE A SER AGENTE DE TRANSFORMACIÓN ECO-CULTURAL}

En $1978,{ }^{2}$ Ivan Illich denuncia la capitalista forma de proceder del sistema escuela y establece los fundamentos frente a la constante resistencia de transformación profunda que necesita el "sistema escolar", que permita romper la estructura y los principios fundantes de dicha institución, quedando fuera de ella los diversos medios de control, las estandarizaciones y el acomodamiento hacia nuevas tecnologías, como metodologías que apuntan hacia el apreciado "siglo de la globalización y las comunicaciones". A estas críticas, Rauber (2004) agrega que Transformación Social se comprende como el proceso de resistencia, creación y construcción integral de lo nuevo, donde el cambio se produce desde abajo, desde adentro, de manera cotidiana y permanente, por lo tanto y en este contexto, uno de los grandes problemas de los fracasos en las distintas reformas educacionales de los países, es el no atreverse a realizar propuestas verdaderamente opuestas a las ya conocidas, siempre existe el temor a los cambios profundos.

Por su parte, cuando hablamos del concepto eco-cultural, nos referimos al cambio en el sistema de existencia de una sociedad y una cultura, no basta con transformarnos

\footnotetext{
SIMCE: Sistema de Medición de la Calidad de la Educación en Chile. PSU: Prueba de Selección Universitaria en Chile.

2 Entre quienes encabezan la corriente de "Un mundo sin escuelas", Illich destaca por su autoridad y por los alcances de su enfoque. Junto a él existen variados autores que enjuician sus revolucionarias ideas, entre ellos: Summer M. Rosen, Judson Jerome, Maxine Greene y Ronald Gross, entre otros.
} 
como grupos de humanos, más bien necesitamos mudar la relacionalidad que tenemos con todo lo que nos rodea.

A partir de estos postulados, ${ }^{3}$ vale el honor (y no la pena) consensuar ideas sobre transformación eco-cultural, comprendida para este trabajo como el desplazamiento de una persona o grupo entre el polo de ser naturaleza y el no ser naturaleza, teniendo como resultado la interacción persona-entorno, donde una transforma a la otra de manera tautológica o autopoiética. En esta dinámica, será transformación eco-cultural positiva la que se acerque al polo "Ser Naturaleza" y negativa la que lleve al polo "No Ser Naturaleza". Siendo un poco más certeros, compartiremos las ideas de Rauber (2004) en cuanto a identificar la transformación como un tránsito permanente y continuo, más que la acción en sí misma.

En esta senda, la escuela del siglo XXI presenta esbozos de transformación, donde se visualizan avances que no son permanentes ni continuos, más bien se destacan por ser efímeros y entrecortados. El caso de la danza es un buen ejemplo de "seudo- transformación", teniendo en cuenta que los estilos dancísticos responden generalmente a lo propuesto por la televisión y los medios de comunicación masivos, más que a los sentidos y significados de infantes y adolescentes, por lo tanto, las mudanzas adquiridas responden a cánones de orden masivo visiblemente influenciados. Nos atrevemos a señalar este estancamiento, porque en pleno año dos mil doce y a pesar de las constantes movilizaciones sociales en diversas localidades del mundo, las escuelas tienden a repetir estereotipos dancísticos que no representan el sentir profundo de los escolares, más bien revelan a un mercado de músicas y vestuarios impuestos por el neo-liberalismo y el capitalismo.

Siguiendo en esta línea, podríamos decir que los adultos que estamos encargados de producir transformaciones educacionales, vamos siendo sutilmente subordinados a satisfacer las supuestas necesidades de los estudiantes. Pero, ¿en qué momento escuchamos sus insuficiencias ecológicas? ¿somos agentes reales de cambio? No podemos desconocer que en los últimos años, tenemos niños y jóvenes que responden a otros parámetros de vida, seres humanos de profundas convicciones que buscan constantemente explicaciones y fundamentos de existencia que no son posibles encontrar en la escuela.

\subsection{LA LÓGICA DE LA NO NATURALEZA EN PROCESO SEUDO - TRANSFORMADOR}

Si retomamos las características de la danza académica, es factible visualizar ejercicios y movimientos que circulan bajo el principio de romper con lo natural. Saltos y giros se destacan por su virtuosidad, mientras los cuerpos de los danzantes se van delineando hacia la delgadez extrema, junto a la elevación del ego por resaltar la belleza y la majestuosidad de la puesta en escena, que generalmente contiene altos costos económicos en materiales, vestuarios e infraestructura. En esta lógica artificial de la técnica, se producen importantes cambios. No obstante, dichas transformaciones se desplazan hacia el polo negativo de la naturaleza.

A estas percepciones dancísticas, un interesante autor brasilero, a pesar de no hablar de danza, nos colabora asertiva y críticamente desde una particular mirada, al comentar lo alejado que nos encontramos de los entornos bióticos:

3 A los que suman diversos autores, como por ejemplo Rudolf Stainer, Leonardo Boff, Edgard Morín, Reichmann, entre otros. 
El ser humano, en su aventura evolutiva, se fue alejando lentamente de su casa común, la tierra. Fue rompiendo los lazos de coexistencia con los demás seres, sus compañeros de eco-evolución. Perdió la memoria sagrada de la unicidad de la vida en sus incontables manifestaciones. Se olvidó de la red de interdependencias entre todos los seres, de su comunión con los vivos y de la solidaridad entre todos. Se colocó en un pedestal. Pretendió, a partir de una posición de poder, someter a todas las especies y todos los elementos de la naturaleza. Tal actitud introdujo la ruptura de la re-ligación de todos con todos (Boff, 2000: 35).

Lo anterior se expresa con la intención de reflexionar y criticar la forma parcelada, individualizada y rutinaria sobre la que estamos trabajando hoy en educación. Nuestros hermanos no humanos, sin embargo, son capaces de entregarse en beneficio de la comunidad a la que pertenecen a través de la búsqueda constante de nuevos escenarios que contribuyen al fortalecimiento de subsistencia. Quizás, si nos detuviéramos a contemplar el trabajo de otros seres vivos, lograríamos comprender el éxito evolutivo de sus procesos, identificando, por ejemplo, el trabajo comunitario de las abejas, donde la reina necesita de la colaboración de las obreras, como las obreras de la reproductividad de su reina. Del mismo modo, podríamos decir que el profesor necesita de la confianza de sus alumnos, como los alumnos de la confianza de sus profesores. Si a esta co-dependencia le agregamos la interacción y complicidad con el entorno, nos acercaríamos al encuentro de sí mismo, apareciendo de esta manera nuevos enfoques dancísticos que precisan ser valorados como propuestas pedagógicas emergentes, en este caso llamada Danza Interacción y no danza intervención, por considerar que, más que invadir espacios, la propuesta invita a la comunicación y la relación sujeto-sujeto como también sujeto-objeto. Esta visión dancística no sólo se sostiene por el deseo de hacer "algo diferente", sino por la posibilidad de hacernos conscientes de un proceso re-ligante.

Pero, ¿qué sucede entonces con técnicas de danza que radican en modelos certeros, predecibles y establecidos? ¿es factible que en ellas se produzcan transformaciones sociales de fondo? Según el modelo de Boff (2002), la lógica de la naturaleza en proceso evolutivo, radica en los siguientes pasos: organización - ruptura del equilibrio - desorganización - nueva relación - nuevo equilibrio - nueva organización, y así continuamente. Sin embargo, a partir de cánones tradicionales de danza, esta lógica sólo podría responder en base a una seudo-transformación. En el siguiente cuadro, podemos apreciar una

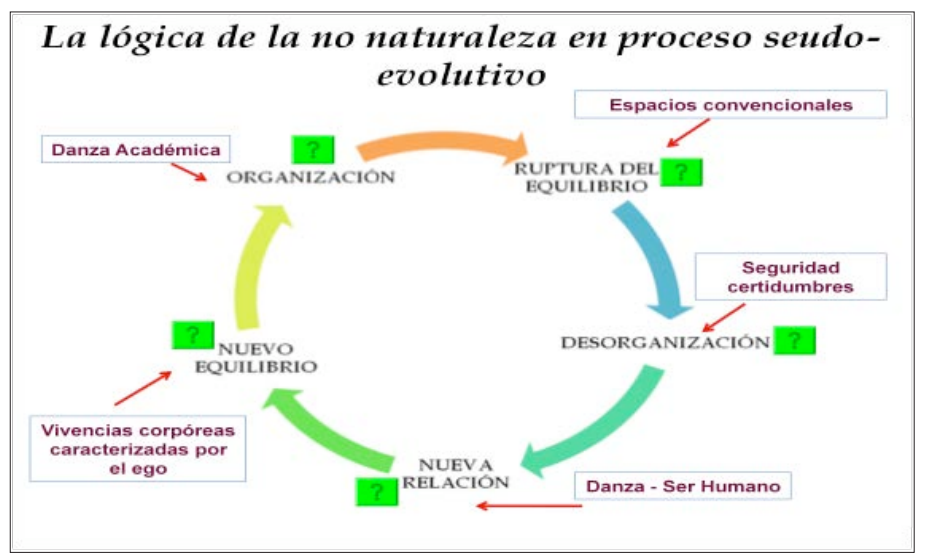

Fig. 1 
comprensión opuesta a la propuesta por Boff (2002), considerando la danza académica como claro ejemplo de convencionalidad:

En el círculo podemos apreciar que la danza académica se presenta como una técnica organizada y definida, trabajando generalmente en espacios y escenarios convencionales (teatros, salas con pisos adecuados e iluminación que destacan la belleza y elegancia de los movimientos). Por su parte, y siguiendo la ruta propuesta por el autor, nos encontramos con que estos espacios producen comodidad, estabilidad y certidumbre, tanto en los danzantes como en el espectador, perdiéndose por tanto la posibilidad de caos y desorganización. Posterior a ello, se observan cambios y transformaciones, pero sólo a nivel de danza - ser humano, quedando la nueva relación supeditada (una vez más) al antropocentrismo. En consecuencia, se obtiene como resultado, un alto nivel de ego, expresado por vivencias corpóreas de magnificencia humana.

De tal modo, este tipo de danza no respondería al modelo evolutivo de Boff (2002), más bien lo contradice y detiene.

\section{DANZA INTERACCIÓN GENERADORA DE SENTIDOS EN EL ÁMBITO ESCOLAR}

\section{1 ¿QUÉ SE ENTIENDE POR DANZA INTERACCIÓN?}

Cuando hablamos de re-ligación, nos referimos a la posibilidad que tenemos de volver a co-existir con el medio. En este contexto, Berman (2004) nos relata una visión de mundo en occidente donde las rocas, los árboles, los ríos y las nubes eran contemplados como algo maravilloso y con vida, y los seres humanos se sentían a sus anchas en este ambiente. El destino personal humano estaba ligado al del cosmos, siendo esta relación la que daba significado a sus vidas. Este tipo de conciencia, a la que él llama "conciencia participativa", involucra coalición o identificación con el ambiente. Habla de una totalidad psíquica que hace mucho ha desaparecido de escena. Este tipo de pensamiento puede describirse mejor como un desencantamiento, una no participación, debido a que insiste en la distinción rígida entre observador y observado. La conciencia científica es una conciencia alineada. Berman (2004: 16) nos dice: "no hay una asociación ectásica4 con la naturaleza, más bien hay una total separación y distanciamiento de ella, sujeto y objeto siempre son vistos como antagónicos, yo no soy mis experiencias y por lo tanto no soy parte del mundo que me rodea".

Al mencionar sujeto-objeto como elementos contrapuestos, el autor nos invita a reflexionar sobre la falta de vínculo con lo que originalmente somos, vale decir, "naturaleza". Como una forma de enfrentar esta patología, recogemos una de las tantas tendencias de la danza contemporánea que propone inter-actuar con aquello que nos rodea. La danza interacción, por tanto, es una manifestación corpórea que transcurre en un espacio comunicativo provocado por la relación dancística entre el bailarín y el entorno, donde se generan cambios y transformaciones, tanto de lo espacios recorridos como de los cuerpos que se envuelven en ellos. En este tipo de expresión, se busca re-significar la comunicación no verbal, desde propuestas no invasivas, vale decir, desde el reconocimiento de sí mismo en cada rincón recorrido, tomando en cuenta la historicidad del lugar visitado

4 Entiéndase como extensión, prolongación, dilatación, distensión. 
como también por los seres que allí habitan. En palabras de Le Breton (2006), podríamos decir que el mundo es la emanación de un cuerpo que lo penetra. A diferencia de lo que sucede en espacios convencionales de desarrollo dancístico, dispuestos para ser moldeados e intervenidos, los lugares no convencionales, llámese ciudades, parques, playas, edificios o ríos, no son espacios neutros ni quietos, más bien son lugares vivos, habitados y transitados al igual que los humanos que proponen interactuar, por lo tanto el traspaso de energías vitales se transforma en un despliegue tautológico de extrañas y nuevas sensaciones corpóreas. No obstante, es relevante destacar, que son los espacios públicos (naturales o no) los que más bien poseen la propuesta de base para la interacción, por tanto somos nosotros, los cuerpos danzantes, los que debemos ir preguntando y descubriendo qué zonas son permitibles abordar.

Al indagar en el concepto Danza Interacción, nos enteramos que no existe una definición teórica acabada y estudiada. Lo que sí podemos encontrar, son ideas relacionadas a Danza Intervención, tendencia particularmente ligada a la vinculación de actividades escénicas (y dancísticas en lo específico de este trabajo) en espacios urbanos, donde se busca dar vida y re-configuraciones a lugares aparentemente neutros e inmóviles. De esta manera, se pretende que, tanto danzantes como espectadores, tengan la oportunidad de acercarse a expresiones artísticas desde zonas y objetos cotidianos de trabajo y convivencia.

En esta búsqueda de nuevos escenarios dancísticos, se localiza un concepto llamado Danza Site Specific, idea entendida como la creación en el espacio in situ. Site Specific nace en el arte de los años 70, mientras que en la danza específicamente, aparece en la Judson Church, ${ }^{5}$ con personajes como Trisha Brown ${ }^{6}$ que llevan la danza, primero, a espacios urbanos y, luego, a creaciones en contacto con la naturaleza, donde también se integra la improvisación in situ. Hoy en día existen numerosos festivales dancísticos que se realizan en espacios naturales con el fin de re-ligar los cuerpos humanos con aguas, bosques y prados.

Ahora bien, en cuanto a estos espacios particularmente bióticos de interacción, donde el encuentro se produce directamente con otros seres vivos y con los cuatro elementos básicos de la naturaleza, se observa que servirán para vivirse y recrearse en y con el arte de nuestra naturaleza donde todo se transforma, danza y encuentra. En este tipo de experiencias, es posible recuperar el sentido profundo de lo intuitivo e instintivo, reciclando principios básicos de técnicas de danza contemporánea: ejercicios de contacto, improvisaciones, trabajo en suelo, incorporación de otras artes (poesía-pintura-esculturasmúsica), entre otras. A través de este tipo de relaciones, la metáfora de los elementos universales genera comunicación retroalimentativa con los cuerpos danzantes. De esta manera, vamos dilucidando que la danza no requiere de espacios específicos ni tampoco de características corporales deslumbrantes, basta nada más sentir y querer despojarse de ataduras que por años han sido impuestas.

5 Judson Dance Theater fue un grupo informal de bailarines que realizaron en la Judson Memorial Church de Nueva York (1962-1964). El grupo de artistas que se formaron son considerados los fundadores de la danza posmoderna. Estos artistas rechazaron los límites de la danza moderna y la teoría de la práctica.

6 Trisha Brown, bailarina y coreógrafa posmodernista estadounidense, nacida en el año 1936. Sus trabajos realizados entre los años 1971 y 1973 fueron diseñados para ser realizados en sitios específicos: espacios públicos de todo tipo, aguas, bailarines en balsas flotantes o caminando con arneses sobre las paredes. De esta manera la artista, trae una sensibilidad intelectual que desafía la corriente principal de la "danza moderna" instalada en la mentalidad de la época. 


\subsection{LA LÓGICA DE LA NATURALEZA EN PROCESO EVOLUTIVO SEGÚN BOFF (2002): SENTIDOS Y SIGNIFICADOS DE LA PROPUESTA}

Para poder discutir sobre la relación ser humano-naturaleza, es preciso hablar de sentido, lo cual nos lleva a indagar en el concepto complejo y fascinante de la existencia. Desde tiempos antiguos se ha descifrado el origen de la realidad de las ideas a partir de la morfología de la materia en su vinculación con el universo. En este razonamiento relacional, hoy encontramos que el significado común de la existencia sería estar en el mundo, referido principalmente a la interacción de nosotros con los objetos y el contexto. La inquietud del presente apartado tiene relación, entonces, con esta necesidad humana de alcanzar nuevas sensaciones que provoquen des-equilibrios en ritmos constantes y repetitivos del quehacer cotidiano. Este afán, se explica como un impulso natural, según Boff (2002), donde la vida surge de cierta ruptura de los equilibrios, lo que provoca auto-organización, mediante el diálogo con el medio.

Conforme a lo discutido en el primer punto de este texto, la lógica de la naturaleza en proceso evolutivo, según el autor, sería: organización - ruptura del equilibrio - desorganización - nueva relación - nuevo equilibrio - nueva organización. Por lo tanto, ahora si es momento de presentar un cuadro relacional que signifique y responda a la propuesta de Boff (2002).

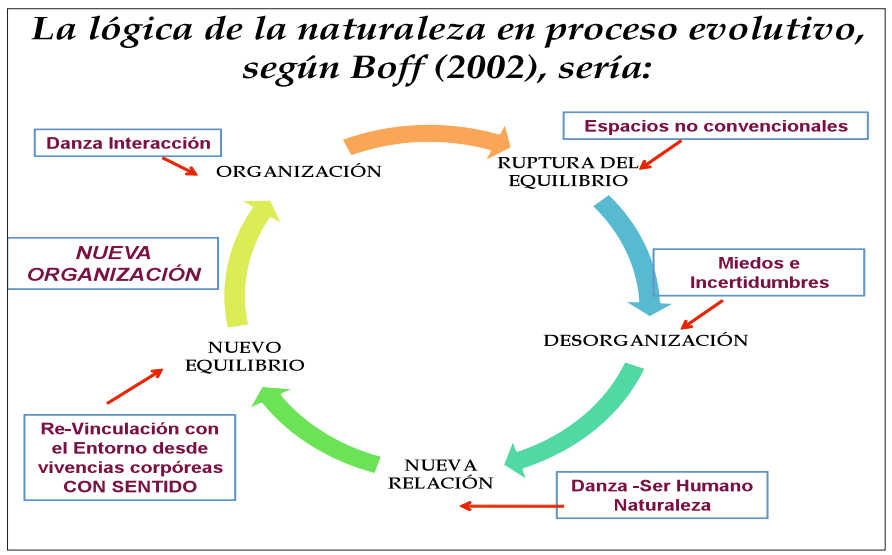

Fig. 2

En esta instancia, podemos interpretar que la danza interacción se presenta como una técnica organizada dentro de su desorganización, trabajando generalmente en espacios y escenarios no convencionales que destacan por sus relieves, diversidad de texturas y atmósfera. Como bien hemos señalado con anterioridad, nos referimos a entornos bióticos y abióticos, donde los cuerpos danzarines se acomodan y ensamblan desde la incomodidad y la búsqueda de acople con ellos. En este desafío, se logra percibir que los espacios que producen miedos e incertidumbres, al mismo tiempo podrían ser provocantes y placenteros, tanto para los danzantes como para los posibles espectadores. Finalmente, se observan cambios y transformaciones, en tanto danza - ser humano - naturaleza, generándose una nueva relación re-ligante con sentido expresada por vivencias corpóreas impregnadas y trascendentes. 
De tal modo, este tipo de danza respondería al modelo evolutivo de Boff (2002), dándole resignificado y validez.

\subsection{TRANSFORMACIÓN ECO-CULTURAL DESDE LA RE-CREACIÓN DANCÍSTICA DE LOS ENTORNOS}

Hay una serie de adjetivos que señalados de manera conjunta, construyen una percepción de cómo estamos sintiendo la sociedad contemporánea: homogeneizada, igualada, achatada, normativizada, masificada. En ciertos segmentos de la población, se ha llegado al punto en que palabras como normal, bueno, correcto o legal, se usan indistintamente como si fueran sinónimos. La búsqueda de transformación nace desde la disconformidad con estimar que lo normal, o peor aún, lo legal, le otorga a los actos humanos la virtud de ser correctos. Necesitamos acercarnos al polo "ser naturaleza", habiendo superado la oposición entre antropocentristas y biocentristas, cambiando posturas del tipo "el humano o el árbol", por "el humano con el árbol". Este proceso no ocurrirá si esperamos sentados que llegue, dado lo que necesitamos y lo que somos: una fuerza geológica planetariamoral que debe descubrir maneras de provocar el despertar hacia las acciones buenas.

La homogeneización de las personas encuentra equivalencia en la homogeneización de los entornos, que a su vez produce homogeneidad en las personas. Modificar esta reciprocidad persona-entorno pareciera ser tarea de arquitectos, si es que nos focalizamos sólo en el rediseño del espacio, pero si además revisamos la posibilidad de intervenir en la percepción del entorno, el foco pasa a la persona.

Ejemplifiquemos con un caso ficticio pero factible. Un joven camina siempre por la misma calle para acceder a su centro de estudios; se aisla en audífonos y lentes oscuros; las dimensiones estandarizadas de líneas rectas, ángulos verticales y horizontales en $90^{\circ}$ y distancias regulares, le permite avanzar con gestos mecánicos que no demandan casi de ajuste, no hay sorpresa. Entonces puede darse el gusto de estar en un entorno en la pretensión fácil de no relacionarse con él. De pronto, un día la rutina se desestabiliza, cuando otros cuatro jóvenes de su edad danzan justo en un espacio que está en su trayecto, son ineludibles y le terminan envolviendo hasta que ya no puede ignorarlos. Su caminar mecánico ya no sirve, se debate entre enojarse, devolverse, golpearles, manifestarles su incomodidad o hablarles y saber por qué lo hacen, pero resuelve silenciar y avanzar mientras los cuatro jóvenes se mantienen a su alrededor como los electrones a un núcleo atómico.

Repentinamente se ve reflejado en ellos, se siente semejante, salvo que él optó por aislarse mientras los danzantes optaron por interaccionar. Llega a la esquina y cruza la calle, los danzantes se devuelven para atrapar otro núcleo atómico. El joven aislado, que ahora se sabe aislado, nunca más podrá transitar en ese espacio sin recordar a los danzantes interactuantes; el sólo recuerdo, asociado al espacio, modifica su relación con el entorno, que ha sido re-creado en una experiencia de 60 metros y 40 segundos. Aún no se da cuenta, pero ha sido empujado, por el hecho de tener un darse cuenta, hacia el polo ser naturaleza; ya no está estable, comienza a sospechar que des-aislarse, es descubrirse como actor cultural en relación con el entorno, se siente un ser eco-cultural aunque aún no nomine su nueva condición. 


\subsection{SENTIDO EDUCATIVO: DANZA - SUJETO - CONOCIMIENTO}

La danza interacción, desde esta perspectiva, nos da la posibilidad de transformar los espacios convencionales en enormes escenografías que dejan de ser neutras y quietas, convirtiéndose en generadora de sentido e inspiración para la re-creación espontánea de dibujos y trayectos que dan nueva vida a lo ya existente. Uno de los aspectos interesantes de los "entornos", es su falta de plasticidad, ya que no son precisamente ellos quienes se amoldan a nuestras curvas corpóreas, más bien somos las personas quienes nos vamos transformando y acomodando a las formas propuestas por el espacio.

Desde este ensamblaje, se podría señalar que el arte es una manifestación no sólo creada por el ser humano inspirada en los fenómenos culturales y ambientales que lo rodean, sino también por otros seres vivos y no vivos, logrando hacer "simbiosis" si es que así lo permitimos. De este modo, poco a poco, vamos creando lazos afectivos con lo que somos. Esta reflexión nace cuando logramos comprender que las ciudades, las habitaciones, los perros de la calle, los grafitis murales, las plazas e incluso las instituciones bancarias, ¡también somos nosotros!, dado que convivimos día a día junto a ellos. Hoy, muchas personas intentamos huir de estos lugares buscando de manera permanente sitios verdes y oxigenados, tendencias de características filogenéticas que no podemos negar. Sin embargo, ¿qué ocurre cuando no tenemos la posibilidad de acceder a estos lugares? Al parecer, en esas instancias, nuestra disposición al trabajo cambia, el mal humor se acentúa y comienzan a aparecer conflictos sociales y personales, que desencadenan la siguiente la pregunta: ¿podremos co-crear o re-crear los espacios que nos rodean a diario desde la comunicación corporal?

Después de todo, según Le Breton (1998: 34) "el mundo lo vamos trazando desde la simbólica corporal, lo que se entiende como una memoria que hay que mantener y alimentar constantemente en el espejo del comportamiento y las palabras de los otros". Desde este punto de vista, encontramos que entre la sensación de las cosas y la sensación de sí mismo se instaura un vaivén y un fluir de energías humanas y no humanas que pueden compenetrarse al danzar "en" y "con" el entorno mediato e inmediato, dando vida, alegría y sentidos a lo aparentemente inerte e inorgánico.

Kuitca (2008) se refiere a que el efecto de la vida es como las fichas de dominó, donde un lado de nosotros se conecta con otro igual, pero el otro lado, necesariamente, está abierto para esperar otro par con la misma configuración. De esta manera, los artistas parecieran buscar actitudes, contextos y personas que los identifican, comenzando a emerger la sensibilidad y, por ende, la creatividad. El autor plantea que la teatralidad es quizás aquello que no ocurre en la sala o en el escenario, sino más bien en las butacas, en los muros, en el ambiente del teatro o de la sala. La mayoría de las veces creamos a partir de la figura o la intención humana. Sin embargo, la producción o los efectos creativos podrían estar en los espacios o los objetos que se relacionan con los humanos, por lo tanto, el ser no es más que él frente a su muralla, a las patas de una mesa, al resplandor de un espejo o al sonido sutil y agudo del teclado de nuestra computadora, entonces diremos que somos más que el ser frente al cosmos, somos también el ser frente a lo doméstico, no se trata de despegarnos del mundo, sino más bien de conectarnos con él, con lo local, con lo afectivo y efectivamente propio, logrando a través de la danza libre, espontánea e indagadora, comunicar emociones, historias y preguntas, teniendo como vehículo corporeidades de diversas composiciones y tendencias. Para este tipo de 
trabajos no necesitamos cuerpos estilizados y ágiles, por el contrario, lo que se intenta rescatar son los cuerpos cotidianos, esas corporeidades que transitan cansadas, nerviosas, enfermas, enamoradas, alertas o lúdicas, rescatándose huellas y significados que son el texto histórico de cada vida.

Desde esta reflexión, el sentido educativo de la danza en interacción con el entorno, radica fundamentalmente en la percepción, la incertidumbre y la identidad generada en cada paso transitado. Es por medio de estos elementos de sentido que logramos llegar a la sensación, de ella a la emoción y de ahí a los sentimientos para luego sumergirnos en la conciencia ${ }^{7}$ (Feitosa, 2006).

En palabras de Barreto (2004), la danza, en su sentido más primitivo y originario, supone la expresión de profundos sentimientos a través de acciones corpóreas. La danza ha sido siempre un medio de liberación y de comunicación. Con frecuencia se convierte en acciones gratuitas que surgen de un impulso interior y no persigue ninguna finalidad más que manifestarse en ese aquí y ahora. Por esta razón, la educación no debería renunciar a favorecer en los educandos este tipo de aprendizajes que facilitan al alumno, como persona, la posibilidad de danzar en el lenguaje que le es más propio. El niño y el adulto necesitan experimentar su corporeidad dejando que afloren libremente sus reacciones primarias y sus sentimientos para construirse desde su verdad.

"El paciente que no ha sentido su propio dolor, no puede entender por qué sufre, sólo cuando sienta lo comprenderá, y sólo cuando comprenda comenzará a curarse" (Santiago, 2004: 24). Tomando las palabras de esta autora, diremos que sólo cuando el ser humano se siente a sí mismo, empieza a conocerse y a comprenderse; a partir de ahí comienza la construcción de su ser personal, manteniendo una relación directamente proporcional entre la auto-percepción y el conocimiento propio.

\section{EXPERIENCIA Y REGISTRO DE DANZA INTER-ACCIÓN}

En coherencia con lo antecedentes expuestos, compartimos parte de un valioso registro vivencial de un estudiante de Pedagogía en Educación Física, que fue capaz de trascender su experiencia performática más allá de lo esperado, al tomar contacto corporal con una casa abandonada en medio de un bosque. Es importante señalar que el relato y la profundidad de sus escritos se encuentran marcados por el trayecto hacia el objetivo de exploración corporal.

\subsection{AL ENCUENTRO DE CUTIPAY, LA AVENTURA Y LA DANZA ${ }^{8}$}

Por: Aaron Huichamán Caravantes (Valdivia - Chile, Diciembre de 2011)

Cutipay es un lugar ubicado en la ciudad de Valdivia justo a orillas de un río del mismo nombre, cuyo significado -en lengua- mapudungun sería: salió del agua. En fin, este escrito no pretende ser un trabajo etnohistórico y menos un documento de investigación social, más

7 La conciencia es un fenómeno privado, en primera persona, que ocurre como parte del proceso íntimo y propio. Está vinculada con conductas externas observables por terceros (Damasio, 2000).

8 Registro en bitácora, realizado por un estudiante de Pedagogía en Educación Física-UACh, Valdivia - Chile 2011. 
bien es una bitácora de campo, donde es plasmado un viaje y la vivencia de lo que significa una ida a aquel lugar. Si bien el viaje tiene un objetivo definido, que es encontrar una casona de colonos alemanes abandonada para generar experiencias de danza en contacto con la casa y la naturaleza, el mío es conocer nuevos lugares y guardarlos en mi alma.

El respeto por el entorno y el manejo del silencio cuando se camina por estos senderos es un principio complejo. El silencio es más que nada para poder enfocarse aun más en el aprendizaje sobre la biodiversidad del sotobosque existente y poder valorar de mejor manera lo que está frente a nuestros ojos.

Pareciese que se estamos a mitad del viaje. Llevamos una hora quince minutos y un cerro respetable en su magnitud hace que nos esforcemos, detrás de él encontramos un "astillero", maestranza dedicada a la fabricación de embarcaciones. Alli todavía laboran hombres serenos y generosos, hijos de una larga tradición en la confección de botes.

A esta altura, la misión principal del viaje de encontrar aquella casona de colonos perdida en el bosque y grabar registros audiovisuales de expresiones dancísticas en sus dependencias, se había visto adornado por muchas cosas más que su origen, se estaba entrelazando con el paisaje y la oralidad de las personas que se encontraban en el camino. De pronto a la distancia se asoma lo que pudiese ser una casona, y claro, ahi yace la casa tapada por árboles de pino. Después de tanto esfuerzo se había llegado al tan anhelado destino, lo primero en notar es la data de la casa, por fuera es incolora, sólo el musgo y otras malezas le dan la tinta a lo que algún día fue este sitio que albergó a familias enteras, la visión es impresionante, aquella construcción está solitaria, escondida a los ojos de varios, nadie sabe durante las horas del día que sucede dentro de ella cuando nadie esta mirándola, sólo el aire y las aves la contemplan.

Nuestra profesora señala que antes de entrar había que visualizarla por fuera, sentir lo que alli ocurría, lo que me parece interesante dado el significado que tiene o que pudo haber tenido esta casona y la delicada tarea de danzar en ella. Para darse a entender, esta casa guarda varias historias, una de ellas según nos dicen, es que fue utilizada para torturar y dar muerte a personas.

Al entrar a la casa se siente un ambiente estremecedor, cruzar el dintel de algo que algún día fue considerado impenetrable, y esto hace fluir varios sentimientos de difícil explicación corporal, puesto que hay que estar allí para sentirlo. Llama la atención en el cielo raso del primer piso unos ganchos, los mismos ganchos que uno ocupa para colgar carne u otro objeto con un peso considerable. El segundo piso, es más acogedor, sobresale la vista por los gigantes ventanales, la escalera muy antigua, como sacada de una película tétrica, muy fascinante.

Es increíble poder tocar y sentir la superficie de la casa por medio del roce corporal. Pensar que al posesionar las manos y el cuerpo en un sitio determinado, allí otra persona las puso antes que yo, es grandioso, es una reconstrucción memorable de la historia que debemos saber valorar. Con todos estos atributos, se hizo lo que se había acordado, una sesión audiovisual de video danza, la cual fue agradable y sencilla.

Bueno con todo esto y aun más, se da por finalizado el viaje, dejando grandes experiencias, tanto grupales como individuales, y un aprendizaje significativo duradero. Quizás el sentido de la ida fue mucho más que ir grabar un trabajo académico, como bien lo ha mencionado nuestra profesora: El viaje a Cutipay a grabar el video-danza, era sólo una excusa para lograr trascendencia e identidad con el entorno. Estas palabras toman un sentido relevante, puesto 
que aquí se está trabajando la parte actitudinal de las personas, los lazos entre compañeros y el aprendizaje de valoración por nuestra identidad fue inmensa y difícilmente se olvidará, es más, uno que otro ya estará pensando en ir una y otra vez a aquel lugar, un lugar con historia propia y de esfuerzo real de la gente que alli vive.

Conforme a este relato, se podría decir que profesores y estudiantes estamos llamados a "evocar los sentidos" que movilizan la educación, romper nuestros miedos y superar la limitación, son desafíos constantes del ser humano, por lo tanto, el trabajo en equipo es factor fundamental para lograr metas y objetivos como comunidad-escuela. Si bien este relato no es escolar, podemos apreciar que el parlante destaca, entre otros muchos aspectos, las experiencias grupales e individuales.

Para Holzapfel (2005), preguntarse por el sentido es preguntar por todo, o sea, por lo existencial y lo metafísico que contienen diversos elementos que lo configuran en el transcurso de las vivencias. Si hablamos de sentido, tendríamos que preguntarnos qué entendemos por este concepto. Con frecuencia aparece dentro del lenguaje cotidiano cuando se busca significar algún hecho o situación humana. Según el autor, el sentido contiene por lo menos 3 acepciones: significado, justificación y orientación. La primera, significado, genera una distinción sobre hechos, cosas o palabras, asignándole un valor desde el propio sujeto. Por su parte, la justificación intenta argumentar los significados emergentes. Mientras que la orientación se encuentra referida a la direccionalidad que se traza al momento de tomar decisiones dentro de la compleja existencia humana.

Es posible que estas dimensiones se sustenten en la emoción y la trascendencia, acoplándose de esta manera cinco generadores de sentido: Vínculo, cobijo, atadura, reiteración y sostén (Holzapfel, 2005: 18-20). Cada uno de ellos no sólo participa en la generación del siguiente, sino que lo potencia de manera sinérgica. Esto sucede frecuentemente en cualquier aspecto de nuestras vidas, si se está hablando en cierta sintonía, es por tanto, el sostén donde el sentido alcanza su máxima expresión. En este caso o ejemplo, Aaron (estudiante que relata) crea un importante vínculo con el entorno, destacando de alguna forma su inquietud por volver al lugar. Al parecer, siente afecto y pertenencia, tanto con el lugar como con la gente que allí habita. Y es que la danza humildemente se va transformando en un gran puente de ligación real con la naturaleza, a tal punto que en el escrito prácticamente desaparece.

\section{APORTES EDUCATIVOS DE LA DANZA-INTERACCIÓN A NIVEL ESCOLAR}

\subsection{FORTALECIMIENTO DE CANALES PERCEPTIVOS Y HABILIDADES CREATIVAS}

La danza interacción a nivel escolar, podría ayudar a que cada niño y niña considere su cuerpo como elemento importante para la apertura de los canales perceptivos, estimulando la gran gama de habilidades creativas que posee. El profesor tendrá la posibilidad de invitar a los estudiantes a recuperar la capacidad de acariciar, olfatear, degustar y desplazarse para recoger mayor información de los entornos que nos circundan, y no sólo oír y ver lo que éste nos propone. De este modo, podemos darle un vuelco a la "hegemonía occidental de la vista y el oído" (Le Breton, 2006), sentidos que en la actualidad se ven sobrecargados de protagonismo hasta el punto de perder la capacidad de escucha y contemplación de sucesos que transitan todos los días muy cerca de nosotros 
y que no logramos identificar. Un ejemplo simple y cotidiano, es el uso desmedido de audífonos y teléfonos celulares, manifestación de individualismo y sentido de identidad a partir de objetos fríos e inertes; también se podrían mencionar las horas frente al televisor o frente a la computadora. Estas acciones nos podrían llevar a reflexionar que no hemos mostrado otra forma de comunicarnos, ya que todo lo que hoy somos capaces de percibir y transmitir lo hacemos principalmente a través de los dos sentidos que han sido relevados y potenciados por las telecomunicaciones.

La estrategia de percibir ampliamente los espacios, conlleva a reconfigurar lo existente por medio de la creatividad, y por tanto a sensibilizarse frente a lo que nos construye. Hoy nos quejamos de la falta de sensibilidad humana, pero, ¿qué estrategias utilizamos a nivel escolar para fortalecerla? Para Ackerman (1993; 1995), cuando nos describimos como seres sensibles, lo que queremos decir es que somos conscientes, por tanto tenemos percepción sensorial. Ser mortales y sensibles es a la vez nuestro pánico y nuestro privilegio. Vivimos atados al cinturón de nuestros sentidos, y aunque ellos permitan expandirnos, también nos limitan y restringen. Para tratar de entender los sentidos desde lo que significa percibir, "debemos tratar de comprender cómo evolucionan, cómo se expanden, cuáles son sus límites, a cuáles hemos puesto un tabú, y qué pueden enseñarnos sobre el fascinante mundo que tenemos el privilegio de co-habitar" (Ackerman, 1993: 17).

Luego de este análisis, se podría justificar la importancia de realizar actividades artístico-corpóreas que inviten a re-ligarnos con la naturaleza. Desde esta mirada, la percepción a través de los diversos conductos, colaborarán con la magia y la ilusión de re-construir un mundo desde la complementariedad.

\subsection{LA INCERTIDUMBRE COMO CAPACIDAD DE ASOMBRO, DESAFÍO Y RIESGO}

Un segundo aporte pedagógico de la danza interacción, es el trabajo desde la "incertidumbre", concepto ampliamente estudiado por Edgar Morin, quien nos permite tomar conciencia de que el mayor aporte de conocimiento del siglo XX es el conocimiento del límite del conocimiento. Morin (1999) señala que todo lo que existe, sólo pudo nacer del caos y la turbulencia, por lo tanto, el cosmos se organizó al desintegrarse. De este modo, la aventura de la vida se encuentra colmada de catástrofes que provocan aniquilaciones de las especies y por tanto el surgimiento de otras. En palabras del mismo autor, "Todo lo que vive debe regenerarse sin cesar: el sol, el ser vivo, la biosfera, la sociedad, la cultura, el amor. Todo lo que es precioso en la tierra es frágil, raro y tiene un destino incierto. Lo mismo sucede con nuestra conciencia" (Morín, 1999: 62-63). En este necesario océano de incertidumbres, es preciso prepararnos para un nuevo mundo y esperar lo inesperado. Es por esta razón, que a nivel educativo-escolar las propuestas pedagógicas debieran ser asombrosas, desafiantes y riesgosas.

La capacidad de asombro es una puerta al conocimiento. Sin asombro no hay conciencia posible de los fenómenos que tenemos por delante, sin él se estará a expensas de lo que nos cuenten, por tanto de los asombros y vivencias de otros. Con el asombro seremos capaces de transitar desde la rutina de lo establecido hasta llegar a nuestra propia gloria, desechando lo que nos encandila. Asombrarse es producir sombra, esto significa que uno de los grandes valores de la danza en interacción con el medio natural, es la posibilidad de vencer la ceguera que nos produce la sobre iluminación de acontecimientos tradicionales, como por ejemplo la repetición de frases coreográficas conocidas y establecidas 
por otros. Este asombro, sin duda está directamente relacionado con el riesgo, capacidad que implica el atreverse a danzar en escenarios no convencionales, comprendiendo este concepto como la probabilidad que suceda un evento no esperado o adverso. Esta rama de la incertidumbre, se encuentra a su vez envuelta por el ímpetu del desafío, contenido que involucra la disposición humana hacia la aventura de expresarse de manera no verbal en espacios que debemos empezar por reconocer, asimilar e incorporar como propios.

Estas capacidades ayudan a desarrollar, principalmente, las habilidades cognitivas de los estudiantes, ya que el danzar en lugares no convencionales, genera desafíos e inestabilidad corporal, permitiendo descubrir rincones y perspectivas espaciales que no estamos acostumbrados a abordar. Por ejemplo, el poder trepar, colgarse, arrastrarse, esconderse y equilibrarse en una plaza o una biblioteca de la ciudad, invita a reconocer el mundo desde los más variados niveles y trayectorias propuestos por los espacios, apareciendo el deleite y el impacto de lo desconocido. Esto último, está referido a las posibilidades corpóreas no descubiertas y a la bondad de entornos, que a pesar de estar permanentemente en el mismo sitio, simplemente no conocemos. El desafío y el riesgo de la danza interacción, son elementos que favorecen el aprendizaje debido al fuerte trabajo emocional de los seres que la vivencian. Según Le Breton, ${ }^{9}$ el riesgo es un gran componente que convoca a la resolución de problemas como mecanismo básico de sobrevivencia. Por otra parte, y en este mismo sentido, el miedo, como emoción primaria, de acuerdo a la clasificación que hace Cassasus (2007), aparece como una herramienta de alerta que permite la protección de los posibles peligros. Este miedo, provocado por el riesgo, se podrá enfrentar gracias a la emergencia de la resiliencia como emoción que actuará para sobreponerse frente a la dificultad. De tal modo, el aprendizaje de niños y jóvenes a través de la danza interacción podría alcanzar significancia y trascendencia.

\subsection{CUIDADO MEDIO AMBIENTAL, PERTENENCIA E IDENTIDAD}

El compromiso con el medio es una habilidad que podría ser trabajada perfectamente desde la danza realizada en lugares no convencionales. El contacto corporal directo con estructuras (bióticas y abióticas) que nos rodean, permitirán a educadores y educandos comprometerse con el cuidado del entorno debido a la vivencia explícita que provoca el situarse desde el otro lado de la vida, vale decir, al danzar con sentido la corporeidad logra comprender que pertenecemos a este mundo y que al mismo tiempo el mundo somos nosotros, por lo tanto su destrucción es también auto-destrucción (Reichmann, 2005). Si lográramos este respeto hacia los entornos, indirectamente conseguiremos que los actores escolares se identifiquen cultural y socialmente con los ambientes que han sido parte de una historia de vida.

En este sentido, es importante rescatar en esta vivencia de danza-naturaleza, que tanto estudiantes como profesores pondrán como valor esencial el "cuidado". Para Boff (2002), la esencia humana no se encuentra tanto en la inteligencia, en la libertad o en la creatividad, pero si en el cuidado. El cuidado es, verdaderamente, el soporte real de la creatividad, de la libertad y de la inteligencia, es decir, en el cuidado identificamos los principios, los valores y las actitudes que convierten la vida en un vivir bien y las

9 Durante seminario dictado por el antropólogo francés David Le Breton en la Universidad Arcis-Escuela de Danza, en octubre de 2008, Santiago de Chile. 
acciones en un recto actuar. Desde esta mirada, se podría decir que está germinando un nuevo paradigma de "re-ligación" con la naturaleza, una nueva posibilidad de volver a fascinarnos y asombrarnos, como también el retorno de sentir compasión por los que sufren; en reflexiones de Boff (2002: 24), "estaríamos entrando en una nueva ternura para con la vida y en un sentimiento auténtico de pertenencia amorosa hacia la Madre Tierra".

En fin, o en comienzo, los aportes del arte o de cualquier manifestación de la humanidad, son sólo razones para favorecer el desarrollo de la vida. Desde esta perspectiva, queda mucho por investigar y proponer. Por ahora, es la danza, quizás mañana serán los viajes al espacio, el lenguajear de los animales o la práctica del silencio. Lo que importa realmente, y considerando las reflexiones de Trigo (2006), es seguir indagando en el bienestar universal; en otros tiempos hubiéramos dicho "bienestar humano". Hoy tratamos de comprender que no somos el centro del universo, dando por fin un gran paso actitudinal hacia la "vida" como foco de reflexión y conocimiento, comprendiendo que el problema no es la danza, la escuela o la educación física, sino más bien la vida en relación.

\section{REFERENCIAS BIBLIOGRÁFICAS}

Ackerman, D. (2005). Magia y misterios de la mente, la maravillosa alquimia del cerebro. Buenos Aires: El Ateneo.

Ackerman, D. (1993). Una historia natural de los sentidos. Barcelona: Anagrama S.A.

Barreto, D. (2004). Danza... enseñanza, sentidos y posibilidades en la escuela. Campinas: Autores asociados.

Berman, M. (2004). El reencantamiento del mundo. Santiago de Chile: Cuatro Vientos.

Boff, L. (2002). El cuidado esencial. Ética de lo humano, compasión por la tierra. Madrid: Trotta.

Boff, L. (2000). El despertar del águila. Madrid: Trotta.

Cassasus, J. (2007). La educación del ser emocional. Santiago: Cuarto Propio.

Castañer, M. (2000). Expresión corporal y danza. Barcelona: Inde.

Cifuentes, M. (2007). Historia social de la danza en Chile: visiones, escuelas y discursos 19401990. Santiago de Chile: Ediciones LOM.

Cifuentes, M. (2009). Danza independiente en Chile: restructuración de una escena. Santiago de Chile: Editorial Cuarto Propio.

Damasio, A. (2000). Sentir lo que sucede, cuerpo y emoción en la fábrica de la conciencia. Santiago de Chile: Andrés Bello.

Feitosa, A. (2006). Mudanzas, horizontes desde la motricidad. Popayán: Universidad del Cauca.

García, M. (1997). La danza en la escuela. Barcelona: Inde.

Holzapfel, C. (2005). A la búsqueda del sentido. Santiago de Chile: Sudamericana.

Illich, I. (1978). Un mundo sin escuelas. México D. F: Nueva Imagen.

Kuica, G. (2007). Entrevista en profundidad una belleza nueva. Santiago: Televisión Nacional de Chile.

Le Breton, D. (2006). El sabor del mundo. Una antropología de los sentidos. Buenos Aires: Nueva Visión.

Libuy, L. (2007). Más que danza y expresividad, un instante de motricidad. Ciencias de la Actividad Física, n. 8, 89-96.

Morin, E. (2005). Introducción al pensamiento complejo. Barcelona: Gedisa.

Morin, E. (2001). Los siete saberes necesarios para la educación del futuro. Barcelona: Paidós Studio. 
Morin, E. (1999). La cabeza bien puesta. Repensar la reforma, reformar el pensamiento. Buenos Aires: Nueva Visión.

Rauber (2004). La transformación social en el siglo XXI. ¿Camino de reformas o revolución? Miradas desde abajo. Pasado y Presente XXI, 1-26.

Reichmann, J. (2005). Un mundo vulnerable. Ensayos sobre ecología, ética y tecnociencia. Madrid: Catarata.

Trigo, E. (2006). Inteligencia creadora, ludismo y motricidad. Popayán: Universidad del Cauca.

Santiago, P. (2004). Expresión corporal y comunicación, teoría y práctica de un programa. Salamanca: Amarú. 